\title{
Article \\ Tunable Adhesive Self-Cleaning Coating with Superhydrophobicity and Photocatalytic Activity
}

\author{
Xuan Wang, Weihua Ao *, Sijia Sun, Han Zhang, Run Zhou, Yangzi Li, Jie Wang and Hao Ding *D \\ Beijing Key Laboratory of Materials Utilization of Nonmetallic Minerals and Solid Wastes, \\ National Laboratory of Mineral Materials, School of Materials Science and Technology, \\ China University of Geosciences, Xueyuan Road, Haidian District, Beijing 100083, China; \\ wangxuan0505@163.com (X.W.); sunsijia@cugb.edu.cn (S.S.); zhanghan0050@163.com (H.Z.); \\ 3003180004@cugb.edu.cn (R.Z.); liyangzi@cugb.edu.cn (Y.L.); 3003170004@cugb.edu.cn (J.W.) \\ * Correspondence: awh0223@cugb.edu.cn (W.A.); dinghao113@126.com (H.D.)
}

Citation: Wang, X.; Ao, W.; Sun, S.; Zhang, H.; Zhou, R.; Li, Y.; Wang, J.; Ding, $\mathrm{H}$. Tunable Adhesive Self-Cleaning Coating with Superhydrophobicity and Photocatalytic Activity. Nanomaterials 2021, 11, 1486. https://doi.org/ 10.3390/nano11061486

Academic Editor: José Antonio Navío

Received: 20 April 2021

Accepted: 1 June 2021

Published: 3 June 2021

Publisher's Note: MDPI stays neutral with regard to jurisdictional claims in published maps and institutional affiliations.

Copyright: (C) 2021 by the authors. Licensee MDPI, Basel, Switzerland. This article is an open access article distributed under the terms and conditions of the Creative Commons Attribution (CC BY) license (https:// creativecommons.org/licenses/by/ $4.0 /)$.

\begin{abstract}
Superhydrophobic coatings with intelligent properties have attracted much attention because of their wide application in many fields. However, there is a limited amount of literature on superhydrophobic coatings whose wettability and adhesion can be adjusted by UV irradiation and calcination at the same time. In this study, amorphous $\mathrm{SiO}_{2}$ microspheres $\left(\mathrm{A}-\mathrm{SiO}_{2}\right)$ and nano- $\mathrm{TiO}_{2}$ particles $\left(\mathrm{N}-\mathrm{TiO}_{2}\right)$ were used to fabricate $\mathrm{A}-\mathrm{SiO}_{2} / \mathrm{N}-\mathrm{TiO}_{2}$ composites by wet grinding, and then, they were modified with polydimethylsiloxane (PDMS) and sprayed onto substrate surfaces to obtain a tunable adhesive superhydrophobic $\mathrm{A}-\mathrm{SiO}_{2} / \mathrm{N}-\mathrm{TiO}_{2} @ \mathrm{PDMS}$ coating. It is worth noting that the wettability and adhesion of the coating to water droplets could be adjusted by UV irradiation and calcination. The mechanisms of the aforementioned phenomena were studied. Moreover, methyl orange solution could be degraded by the coating due to its photocatalysis. The as-prepared coating had good adaptation to different substrates and outdoor environments. Moreover, the surfaces of these coatings exhibited the same liquid repellency towards different droplets. This research provides an environmental strategy to prepare advanced self-cleaning coatings.
\end{abstract}

Keywords: superhydrophobicity; photocatalytic activity; tunable adhesion; $\mathrm{TiO}_{2} ; \mathrm{PDMS}$

\section{Introduction}

The "lotus effect" [1] and the "rose effect" [2] are the two most representative superhydrophobic biological phenomena in nature. Both lotus leaf and rose petal surfaces are superhydrophobic. However, lotus leaf surfaces have low adhesive forces to water droplets, which means water can roll off them easily and remove the dust attached to their surfaces. This is defined as the "lotus effect". Unlike lotus leaf surfaces, the rose petal surfaces have high adhesive forces to water droplets, and they cannot roll off their surfaces easily. The study of these phenomena can not only reveal the scientific principles but also solve some engineering problems through practical application. Superhydrophobic surfaces such as lotus leaf surfaces can be used for self-cleaning coatings [3,4], oil-water separation [5,6], anti-corrosion [7], and anti-icing [8]. Meanwhile, superhydrophobic surfaces such as rose petal surfaces can be used for the no-loss transport of microdroplets $[9,10]$ in biology or medicine.

Apart from dust, organic pollutants often attach to the surfaces of building exterior walls. It is difficult to remove the organic pollutants only by the rolling of water droplets from the coating surfaces, even if they are lotus-like self-cleaning coatings. Moreover, the accumulation of these organic pollutants results in the loss of superhydrophobicity [11]. Fortunately, the organic pollutants can be degraded effectively by the photocatalytic activity of some semiconductors. Therefore, the advanced superhydrophobic self-cleaning coating should also have photocatalytic activity. Among these semiconductors, $\mathrm{TiO}_{2}$ has the advantages of excellent photocatalytic activity, chemical inertness, and non-toxicity [12-15]. In recent years, it has 
attracted great interest in the preparation of superhydrophobic materials with photocatalytic activity using $\mathrm{TiO}_{2}$. Parkin [16] et al. prepared a superhydrophobic film with photocatalytic activity through direct incorporation of $\mathrm{TiO}_{2}$ into a PDMS by aerosol-assisted chemical vapor deposition. However, the superhydrophobic film must be based on PDMS, which does not have good adaptability to other substrates. Seeger [17] et al. prepared a superhydrophobic film with $\mathrm{TiO}_{2}$ nanoparticles, silicone nanowires, and polyethylene. The static contact angle of its surfaces reached $168^{\circ}$, and the organic pollutants could be degraded under UV irradiation. Nevertheless, the preparation process is complicated, harsh, time consuming, and not suitable for large-scale applications. Lyons [18] et al. reported a multifunctional $\mathrm{TiO}_{2} /$ high-density polyethylene nanocomposite surface. The static contact angle of the surface reached $158^{\circ}$, but it decreased to $120^{\circ}$ after UV irradiation. This showed that the coating cannot maintain superhydrophobicity under UV irradiation. Therefore, it could not be used outdoors. Wu [19] et al. fabricated a self-healing superhydrophobic coating with polystyrene, fluorine compounds, and fluorine compound-modified $\mathrm{SiO}_{2}$ and $\mathrm{TiO}_{2}$. However, not only are fluorides expensive, but they are also harmful to the environment, which limits their large-scale application [20,21].

Herein, $\mathrm{N}-\mathrm{TiO}_{2}$ was loaded onto $\mathrm{A}-\mathrm{SiO}_{2}$ surfaces by the hydrophobic agglomeration method. Then, $\mathrm{A}-\mathrm{SiO}_{2} / \mathrm{N}-\mathrm{TiO}_{2}$ composite particles were modified with PDMS. Finally, the modified $\mathrm{A}-\mathrm{SiO}_{2} / \mathrm{N}-\mathrm{TiO}_{2}$ composite particles were sprayed onto substrate surfaces, and the $\mathrm{A}-\mathrm{SiO}_{2} / \mathrm{N}-\mathrm{TiO}_{2} @ \mathrm{PDMS}$ coatings with superhydrophobicity and photocatalytic activity were formed after drying. The wettability of the coating could be adjusted by UV irradiation and calcination. Furthermore, the as-prepared coating had good adaptability to different types of substrates, and methyl orange could be degraded by $\mathrm{A}-\mathrm{SiO}_{2} / \mathrm{N}-\mathrm{TiO}_{2} @ \mathrm{PDMS}$ under UV irradiation. Moreover, the coating had the advantages of environmental protection (no organic solvent, such as hexane or toluene), low cost, and powerful operability. Therefore, the coating has a wide range of applications.

\section{Materials and Methods}

\subsection{Materials}

A-SiO ${ }_{2}$ was supplied by Jiaozuo Fluoride New Energy Technology Co., Ltd. (Jiaozuo, Henan, China). The $\mathrm{N}-\mathrm{TiO}_{2}$ used in this study was commercially available. Polydimethylsiloxane was provided by Aladdin Reagents Co., Ltd. (Shanghai, China). Sodium oleate and grade sodium stearate were purchased from Beijing Chemical Works (Beijing, China). Sulfuric acid $\left(\mathrm{H}_{2} \mathrm{SO}_{4}\right)$ and sodium hydroxide $(\mathrm{NaOH})$ used in the experiments were supplied by Beijing Chemical Industry Group Co., Ltd. (Beijing, China). They were all analytical agents. Deionized water and ethanol were also used.

\subsection{Preparation Methods}

The preparation process of the A- $\mathrm{SiO}_{2} / \mathrm{N}-\mathrm{TiO}_{2} @ \mathrm{PDMS}$ coating is shown in Figure 1. The first step was the preparation of the $\mathrm{A}-\mathrm{SiO}_{2} / \mathrm{N}-\mathrm{TiO}_{2}$ composites with the hydrophobic aggregation method [22]. In brief, $5 \mathrm{~g}$ of $\mathrm{A}-\mathrm{SiO}_{2}$ and $20 \mathrm{~g}$ of $\mathrm{N}-\mathrm{TiO}_{2}$ were added into two beakers, which were dispersed by adding 10 times the mass of distilled water under continuous agitation at $50^{\circ} \mathrm{C}$. Then, $0.05 \mathrm{~g}$ of sodium oleate and $0.2 \mathrm{~g}$ of sodium stearate were dissolved in a small amount of water at $50{ }^{\circ} \mathrm{C}$. The sodium oleate and sodium stearate solutions were added to $\mathrm{A}-\mathrm{SiO}_{2}$ and $\mathrm{N}-\mathrm{TiO}_{2}$ suspensions, respectively, and they were stirred for $1 \mathrm{~h}$. Finally, the modified $\mathrm{N}-\mathrm{TiO}_{2}$ suspension was added dropwise to the modified $\mathrm{A}-\mathrm{SiO}_{2}$ suspension. After stirring for 90 min at $50^{\circ} \mathrm{C}$ under $\mathrm{pH}=9$, the $\mathrm{A}-\mathrm{SiO}_{2} / \mathrm{N}-$ $\mathrm{TiO}_{2}$ suspension was obtained, which was dried at $105^{\circ} \mathrm{C}$, and then the $\mathrm{A}-\mathrm{SiO}_{2} / \mathrm{N}-\mathrm{TiO}_{2}$ composites were obtained. 


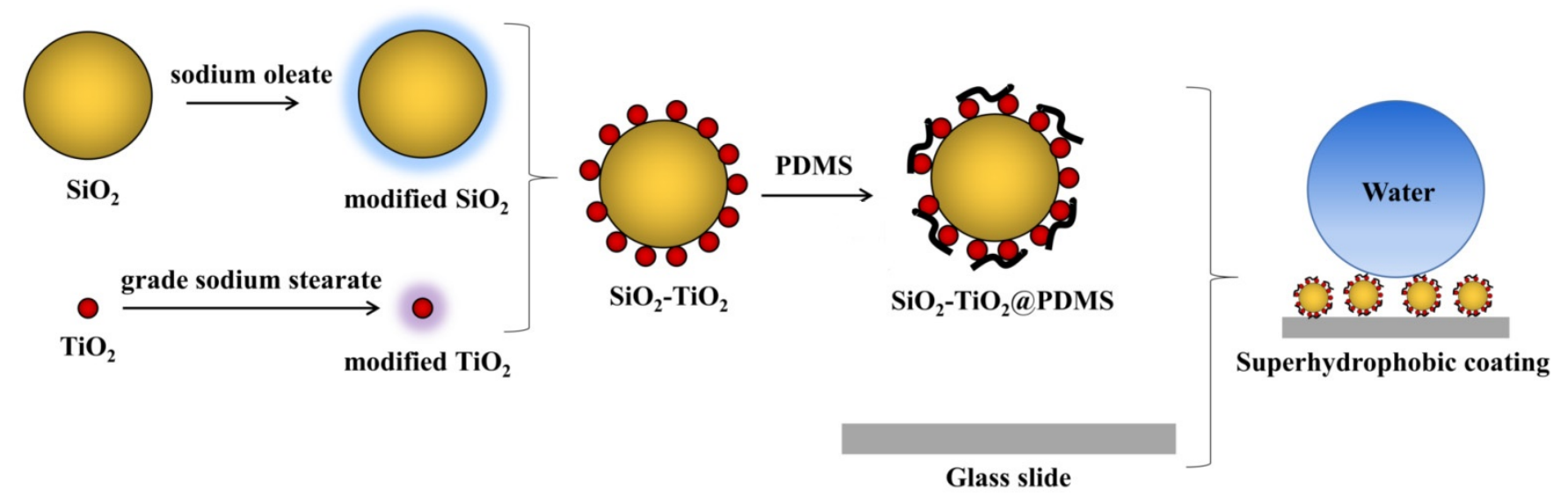

Figure 1. Preparation flowchart of superhydrophobic A-SiO $2 / \mathrm{N}-\mathrm{TiO}_{2} @ \mathrm{PDMS}$ coating.

In the second step, the superhydrophobic A- $\mathrm{SiO}_{2} / \mathrm{N}-\mathrm{TiO}_{2} @ \mathrm{PDMS}$ coating was fabricated by the spraying method, which includes the following steps: $10.0 \mathrm{~g}$ ethanol, $2.0 \mathrm{~g}$ $\mathrm{A}-\mathrm{SiO}_{2} / \mathrm{N}-\mathrm{TiO}_{2}$ composites, and $0.5 \mathrm{~g}$ PDMS are added to a beaker; subsequently, they are stirred for $30 \mathrm{~min}$ and sprayed onto the substrate surfaces; finally, the superhydrophobic coating is obtained after drying at $60^{\circ} \mathrm{C}$.

\subsection{Characterizations}

Water contact angles (WCAs) were used to evaluate the wettability of the surfaces. Contact angle hystereses (CAHs) and the surface adhesive force to water droplets were used to evaluate the adhesion of the surfaces to water droplets. The experiments of photocatalytic degradation were performed, and methyl orange solution was used as the degradation object. The detailed description of the aforementioned measurements and characterizations can be seen in the Supporting Information.

\section{Results and Discussion}

\subsection{Wettability and Adhesion}

The WCAs, CAHs, adhesion forces to water droplets, and their changes after UV irradiation and calcination were measured. The results are displayed in Table S1 and Figure 2. It was observed that the WCA of the coating was $151.2^{\circ}$. After UV irradiation for $1 \mathrm{~min}$ and $8 \mathrm{~h}$, the WCAs of the coatings increased to $158.0^{\circ}$ and $158.1^{\circ}$, respectively. After calcination at $400{ }^{\circ} \mathrm{C}$ for $30 \mathrm{~min}$, the WCA of the coating increased to $159.7^{\circ}$. The results illustrate that the coating had excellent superhydrophobicity, photostability, and thermal stability. Moreover, the thermal stability of the as-prepared coating was further analyzed according to the TG results of $\mathrm{A}-\mathrm{SiO}_{2} / \mathrm{N}-\mathrm{TiO}_{2}$ and $\mathrm{A}-\mathrm{SiO}_{2} / \mathrm{N}-\mathrm{TiO}_{2} @ \mathrm{PDMS}$, which can be seen in the Supporting Information (Figure S1). The adhesion forces of the coating to water droplets are shown in Table S1 and Figure 2b. The adhesion force of the coating to a water droplet was as high as $106.1 \mu \mathrm{N}$ before UV irradiation, and the water droplet could not roll off its surface. After UV irradiation for $1 \mathrm{~min}$, the adhesion force of the surface to water droplets decreased sharply to $10.4 \mu \mathrm{N}$, and the $\mathrm{CAH}$ was $3.4^{\circ}$. After calcination at $400{ }^{\circ} \mathrm{C}$ for $30 \mathrm{~min}$, the $\mathrm{CAH}$ of the coating was $2.3^{\circ}$. It was observed that the coating surface had transformed into a typical lotus-like surface from a rose petal-like surface after UV irradiation and calcination. Due to UV and sunlight irradiation, the environmental conditions that the self-cleaning coatings must face are inevitable, and it is important that the coating maintains the superhydrophobicity and that it adopts low adhesion to water droplets under UV irradiation. This would be beneficial for the as-prepared coating used as an outdoor self-cleaning coating. 


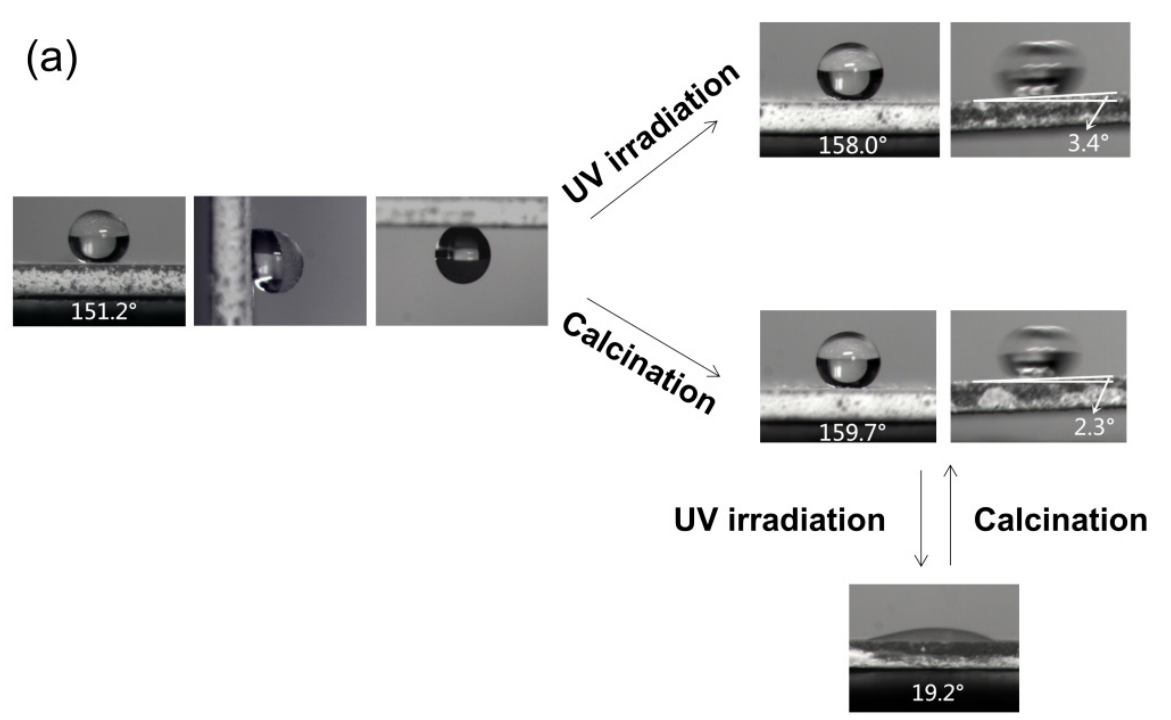

(b)

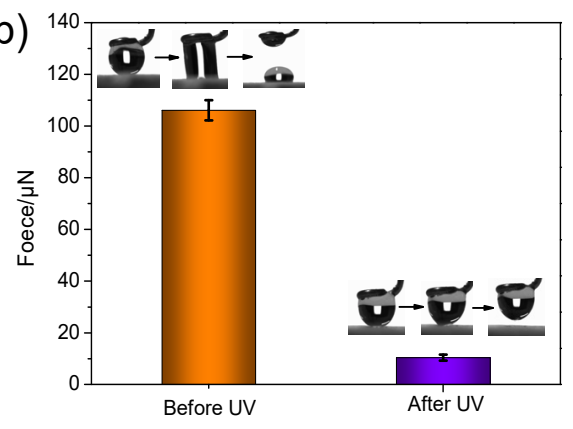

(c)

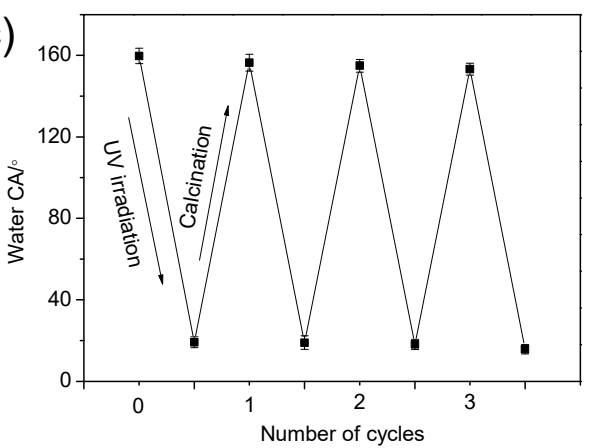

Figure 2. (a) The changes in the coating's wettability and adhesion to water droplets before and after UV irradiation and calcination. (b) The adhesion force of the coating to a water droplet before and after UV irradiation. (c) The changes in WCAs of the coating after alternate UV irradiation and calcination.

The experimental results also exhibited that the calcined coating surface changed from the superhydrophobic state $\left(\mathrm{CA}=159.7^{\circ}\right)$ to the hydrophilic state $\left(\mathrm{CA}=19.2^{\circ}\right)$ after UV irradiation for $2 \mathrm{~h}$. Interestingly, the hydrophilic surface could return to the original superhydrophobic state after calcination at $400{ }^{\circ} \mathrm{C}$ for $2 \mathrm{~h}$. Eventually, the coating surface became hydrophilic after three cycles of UV irradiation and calcination (Figure 2c). It was observed that the wettability of the coating could be adjusted by alternating UV irradiation and calcination for a certain number of times.

\subsection{Self-Cleaning Properties}

\subsubsection{Self-Cleaning Process and Principle}

It is suggested that the self-cleaning properties of the coating include the "lotus effect" and photocatalytic activity. The process and principle of the self-cleaning effect are shown in Figure 3, which mainly include three parts: (1) The organic pollutants on the coating surface are degraded by photocatalysis under UV or sunlight. (2) The superhydrophobicity of the coating is further enhanced under UV or sunlight, and its adhesion to water droplets decrease sharply. The surface of the coating becomes a self-cleaning surface like the lotus leaf. (3) When it rains, the raindrops roll off the coating surface and remove the dust attached to the coating surface. 


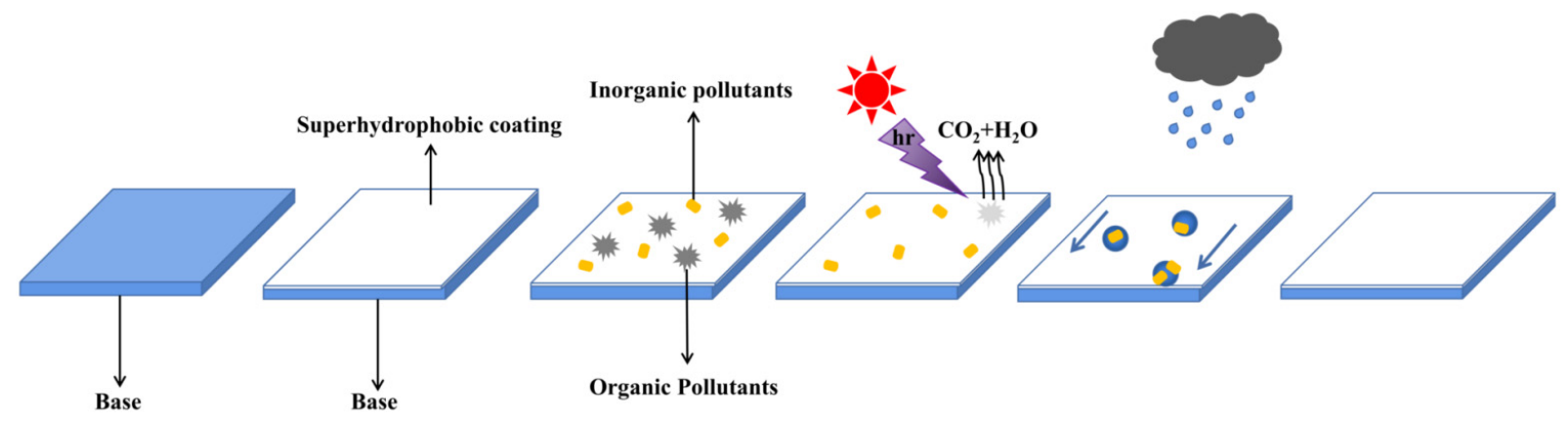

Figure 3. Schematic diagram of the self-cleaning process.

\subsubsection{Photocatalytic Degradation and the "Lotus Effect"}

Figure 4 a displays the results of the photodegradation by $\mathrm{A}-\mathrm{SiO}_{2}, \mathrm{~N}-\mathrm{TiO}_{2}, \mathrm{~A}-\mathrm{SiO}_{2} / \mathrm{N}-$ $\mathrm{TiO}_{2}$, and $\mathrm{A}-\mathrm{SiO}_{2} / \mathrm{N}-\mathrm{TiO}_{2} @ \mathrm{PDMS}$ under UV irradiation. The $\mathrm{C} / \mathrm{C}_{0}$ values of the samples decreased slightly in the stage of dark reaction, indicating that these samples have no adsorption on methyl orange. In the stage of photoreaction, the $\mathrm{C} / \mathrm{C}_{0}$ value of the dilution added with $\mathrm{A}-\mathrm{SiO}_{2}$ decreased slightly, demonstrating that $\mathrm{A}-\mathrm{SiO}_{2}$ had no photocatalytic property. However, the suspensions were decolorized by $\mathrm{N}-\mathrm{TiO}_{2}$ and $\mathrm{A}-\mathrm{SiO}_{2} / \mathrm{N}-\mathrm{TiO}_{2}$ in $20 \mathrm{~min}$. Moreover, the $\mathrm{C} / \mathrm{C}_{0}$ of the suspensions decreased to 0.02 , indicating the degradation rate was $98 \%$. This illustrates that $\mathrm{N}-\mathrm{TiO}_{2}$ and $\mathrm{A}-\mathrm{SiO}_{2} / \mathrm{N}-\mathrm{TiO}_{2}$ had good photocatalytic degradation activities. However, it was found that $\mathrm{A}-\mathrm{SiO}_{2} / \mathrm{N}-\mathrm{TiO}_{2} @ \mathrm{PDMS}$ floated on the reaction solution surface and did not fully mix with it because of the superhydrophobicity. Even so, the $\mathrm{C} / \mathrm{C}_{0}$ of the dilution reached 0.12 , illustrating that the degradation rate was $87.7 \%$. Therefore, it is inferred that the as-prepared coating had a photocatalytic effect on organic compounds.

The "lotus effect" of the coating was verified by a simple simulation experiment. Figure $4 \mathrm{~b}$ presents the experimental process and result. Some dust was spread on its surface, which was irradiated by UV light for $1 \mathrm{~min}$. Then, the coating was placed in a glass dish at a certain angle, allowing for the soil on its surface to be cleaned by the falling water, which is similar to the "lotus effect".

\subsection{Liquid Repellency and Adaptability}

As is well known, there are many types of outdoor substrates, and their surfaces face harsh environments, including contact with different liquids. Therefore, superhydrophobic coatings can be widely used only if they have outstanding adaptability to various substrates while exhibiting liquid repellency and low adhesion to different liquids. To investigate the adaptability of the coating to different substrates, A-SiO $2 / \mathrm{N}-\mathrm{TiO}_{2} @ \mathrm{PDMS}$ was sprayed onto the surfaces of wood, foam, concrete block, and brick, and then they were exposed to UV light for $1 \mathrm{~min}$. Furthermore, the wettability of these surfaces to water, $\mathrm{NaOH}$ solution, $\mathrm{HCl}$ solution, and methyl orange solution was investigated. Figure $5 \mathrm{a}, \mathrm{b}$ show that the above-mentioned droplets spread almost completely on the glass slide surface, illustrating that the surface of the glass slide was hydrophilic. However, the surface sprayed with $\mathrm{A}-\mathrm{SiO}_{2} / \mathrm{N}-\mathrm{TiO}_{2} @ \mathrm{PDMS}$ and irradiated by UV light exhibited excellent liquid repellency towards the above-mentioned droplets, and they were spherical in shape on the abovementioned surfaces. Table S2 shows the WCAs of the surfaces in Figure $5 a, b$ to different droplets. The $\mathrm{CAs}$ of a glass slide to water, $\mathrm{HCl}$ solution, $\mathrm{NaOH}$ solution, and methyl orange solution were $45.6^{\circ}, 41.2^{\circ}, 23.5^{\circ}$, and $43.1^{\circ}$, respectively, while the CAs of the surfaces sprayed with $\mathrm{A}-\mathrm{SiO}_{2} / \mathrm{N}-\mathrm{TiO}_{2} @ \mathrm{PDMS}$ and irradiated by UV light for 1 min were $158.0^{\circ}, 156.4^{\circ}, 153.8^{\circ}$, and $155.8^{\circ}$, respectively. Furthermore, the above-mentioned droplets remained sphere on the coating surface when it was mechanically damaged by a knife (Figure 5c). This indicates that the coating had a good mechanical stability. As can be seen from Figure $5 \mathrm{~d}-\mathrm{g}$, the above-mentioned droplets spread quickly when they were dripping 
on the surfaces of wood, foam, concrete block, and brick, indicating that the surfaces of these substrates were hydrophilic. However, after being sprayed with $\mathrm{A}-\mathrm{SiO}_{2} / \mathrm{N}-\mathrm{TiO}_{2} @ \mathrm{PDMS}$ and illuminated by UV light, these surfaces showed superhydrophobic, and the droplets were sphere in shape on these surfaces. The results suggest that the as-prepared coating had good adaptability to different substrates and showed the same liquid repellency towards different liquids. Therefore, the as-prepared $\mathrm{A}-\mathrm{SiO}_{2} / \mathrm{N}-\mathrm{TiO}_{2} @ \mathrm{PDMS}$ can be used to construct self-cleaning coatings on the surfaces of various substrates.

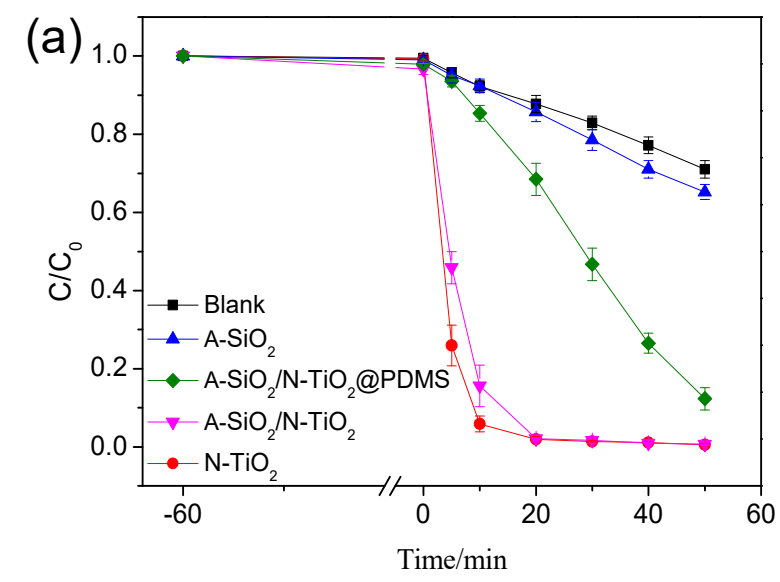

(b)

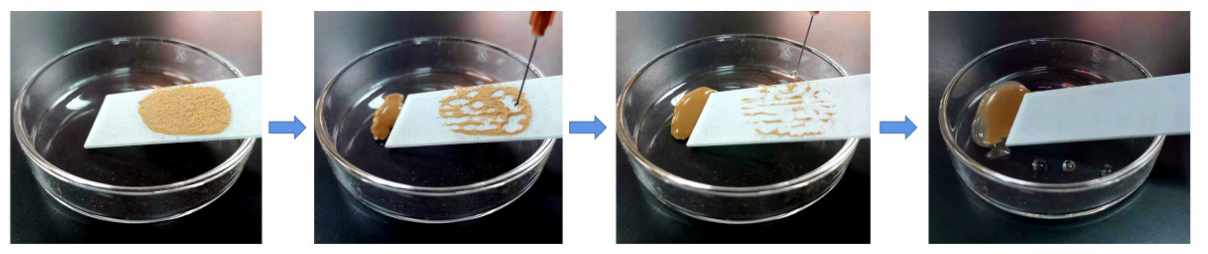

Figure 4. (a) Photodegradation of methyl orange by $\mathrm{A}-\mathrm{SiO}_{2} / \mathrm{N}-\mathrm{TiO}_{2} @ \mathrm{PDMS}$ and other samples; (b) simulation experiment of the "lotus effect".
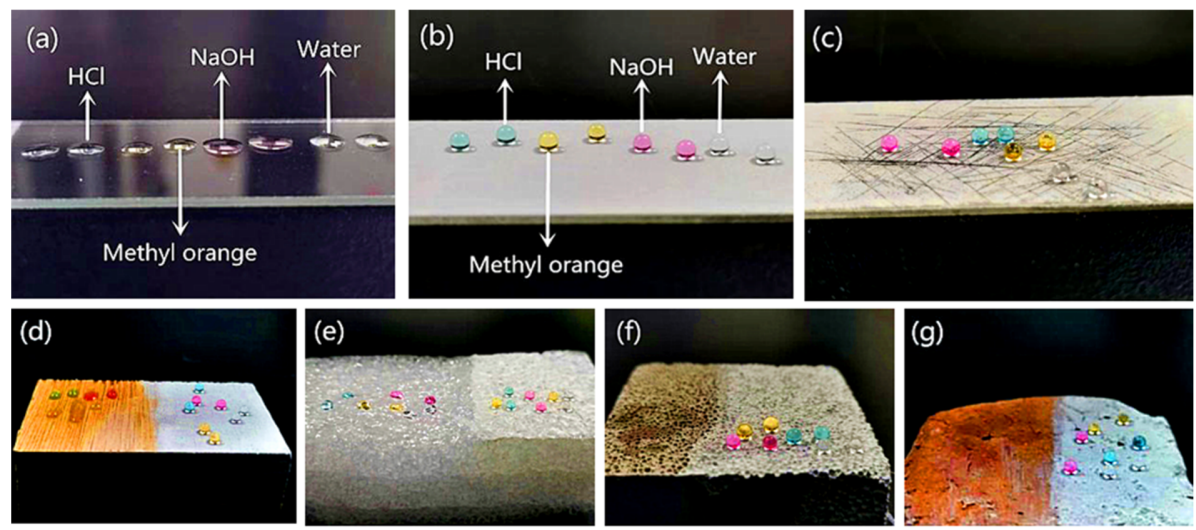

Figure 5. Wettability of the surfaces of (a) a glass slide, (b) the $\mathrm{A}-\mathrm{SiO}_{2} / \mathrm{N}-\mathrm{TiO}_{2} @ \mathrm{PDMS}$ coating after UV irradiation, and (c) the mechanically damaged $\mathrm{A}-\mathrm{SiO}_{2} / \mathrm{N}-\mathrm{TiO}_{2} @ \mathrm{PDMS}$ coating after UV irradiation to water, $\mathrm{HCl}, \mathrm{NaOH}$, and methyl orange solution droplets, respectively; wettability of the surfaces of (d) wood, (e) foam, (f) concrete, and (g) brick before (left) and after (right) being sprayed with $\mathrm{A}-\mathrm{SiO}_{2} / \mathrm{N}-\mathrm{TiO}_{2} @ \mathrm{PDMS}$ and UV irradiation to water, $\mathrm{HCl}, \mathrm{NaOH}$, and methyl orange solution, respectively.

\subsection{Durability}

To investigate the adaptability and durability of the $\mathrm{A}-\mathrm{SiO}_{2} / \mathrm{N}-\mathrm{TiO}_{2} @ \mathrm{PDMS}$ coating to the outdoor environment, it was placed outdoor for 3 months. Then, the changes in the 
WCAs and photocatalytic degradation effect were measured. The results are displayed in Figure 6. The WCA of the as-prepared coating was $155.7^{\circ}$ after being placed outdoors for 3 months, which gave a barely measurable reduction. The $C / C_{0}$ value of the methyl orange dilution was 0.16 , indicating the degradation rate was $84.4 \%$. An obvious decrease was not observed when compared with the original degradation rate of $87.7 \%$. Therefore, the as-prepared coating has good adaptability to the outdoor environment, and it has the potential to be used outdoors for a long time.
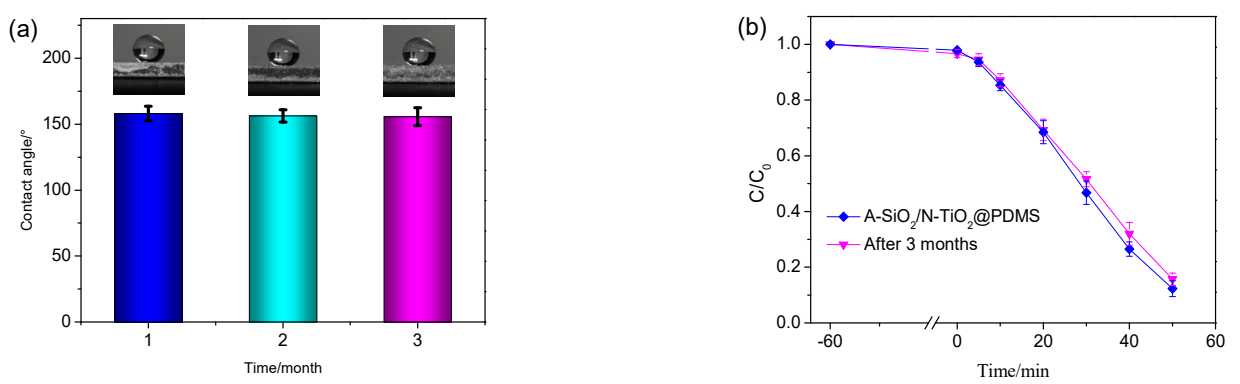

Figure 6. The changes in (a) WCAs and (b) photocatalytic degradation effects of the $\mathrm{A}-\mathrm{SiO}_{2} / \mathrm{N}$ $\mathrm{TiO}_{2} @ P D M S$ coating after being placed outdoors for 3 months.

\subsection{Morphology and Structure}

\subsubsection{Morphology}

To investigate the structures of the samples, SEM was carried out. Figure $7 \mathrm{a}, \mathrm{b}$ are SEM images of $\mathrm{A}-\mathrm{SiO}_{2}$ and $\mathrm{N}-\mathrm{TiO}_{2}$, respectively. Figure 7 a shows that $\mathrm{A}-\mathrm{SiO}_{2}$ was composed of spherical particles dispersed from each other with smooth surfaces, and the particle size was between $0.5 \mu \mathrm{m}$ and $5 \mu \mathrm{m}$. As is shown in Figure $7 \mathrm{~b}$, the granular $\mathrm{N}^{-\mathrm{TiO}_{2}}$ with a particle size of $0.2-0.3 \mu \mathrm{m}$ was a regular aggregate. Figure 7c,e are SEM images of A$\mathrm{SiO}_{2} / \mathrm{N}-\mathrm{TiO}_{2}$. It can be seen that $\mathrm{N}-\mathrm{TiO}_{2}$ was uniformly loaded onto the $\mathrm{A}-\mathrm{SiO}_{2}$ surfaces, and the $\mathrm{A}-\mathrm{SiO}_{2} / \mathrm{N}-\mathrm{TiO}_{2}$ particles showed good dispersity. The structure of $\mathrm{A}-\mathrm{SiO}_{2} / \mathrm{N}-\mathrm{TiO}_{2}$ is similar to that of the lotus leaf, which has micro-scale mastoids and nano-scale rods on its surface.

Figure $7 \mathrm{~d}$ is an SEM image of the as-prepared coating surface. The $\mathrm{A}-\mathrm{SiO}_{2} / \mathrm{N}$ $\mathrm{TiO}_{2} @ \mathrm{PDMS}$ suspension was sprayed on the surface of the substrate to form a honeycomblike structure. Figure 7e shows the element distribution on the $\mathrm{A}-\mathrm{SiO}_{2} / \mathrm{N}-\mathrm{TiO}_{2}$ surfaces. It can be seen that $\mathrm{O}$ and $\mathrm{Si}$ were distributed in the contour range of spherical particles in the scanning area, reflecting the property of $\mathrm{A}_{-} \mathrm{SiO}_{2}$. Moreover, Ti was evenly distributed in the scanning area and corresponded to the position of $\mathrm{A}-\mathrm{SiO}_{2}$. It was proved that $\mathrm{N}-\mathrm{TiO}_{2}$ had been loaded onto the $\mathrm{A}-\mathrm{SiO}_{2}$ surfaces successfully.

Figure $7 \mathrm{f}-\mathrm{h}$ are TEM images of $\mathrm{A}-\mathrm{SiO}_{2} / \mathrm{N}-\mathrm{TiO}_{2}$. The morphology of $\mathrm{A}-\mathrm{SiO}_{2} / \mathrm{N}-\mathrm{TiO}_{2}$ can be seen in Figure $7 \mathrm{f}$, which shows that the $\mathrm{A}-\mathrm{SiO}_{2}$ was approximately $3 \mu \mathrm{m}$ in diameter and was covered by $\mathrm{N}-\mathrm{TiO}_{2}$. Figure $7 \mathrm{~g}$ is an enlarged image of Figure $7 \mathrm{f}$. The lattice fringe of $\mathrm{N}-\mathrm{TiO}_{2}$ can be seen, and the average size of $\mathrm{N}^{-\mathrm{TiO}_{2}}$ was $20 \mathrm{~nm}-30 \mathrm{~nm}$. The lattice fringes in the selected area can be transformed into diffraction spots by Fourier transform, and the results are displayed in Figure $7 \mathrm{~h}$. The crystal plane spacing of $\mathrm{N}^{-\mathrm{TiO}_{2}}$ can be divided into two types. The crystal plane spacings of $0.352 \mathrm{~nm}$ and $0.189 \mathrm{~nm}$ correspond to the (101) and (200) crystal plane of anatase, respectively. The crystal plane spacings of $0.325 \mathrm{~nm}$ and 0.249 $\mathrm{nm}$ correspond to the (110) and (101) crystal plane of rutile, respectively. The results show that $\mathrm{N}-\mathrm{TiO}_{2}$ included anatase and rutile, which were consistent with the results of XRD. 

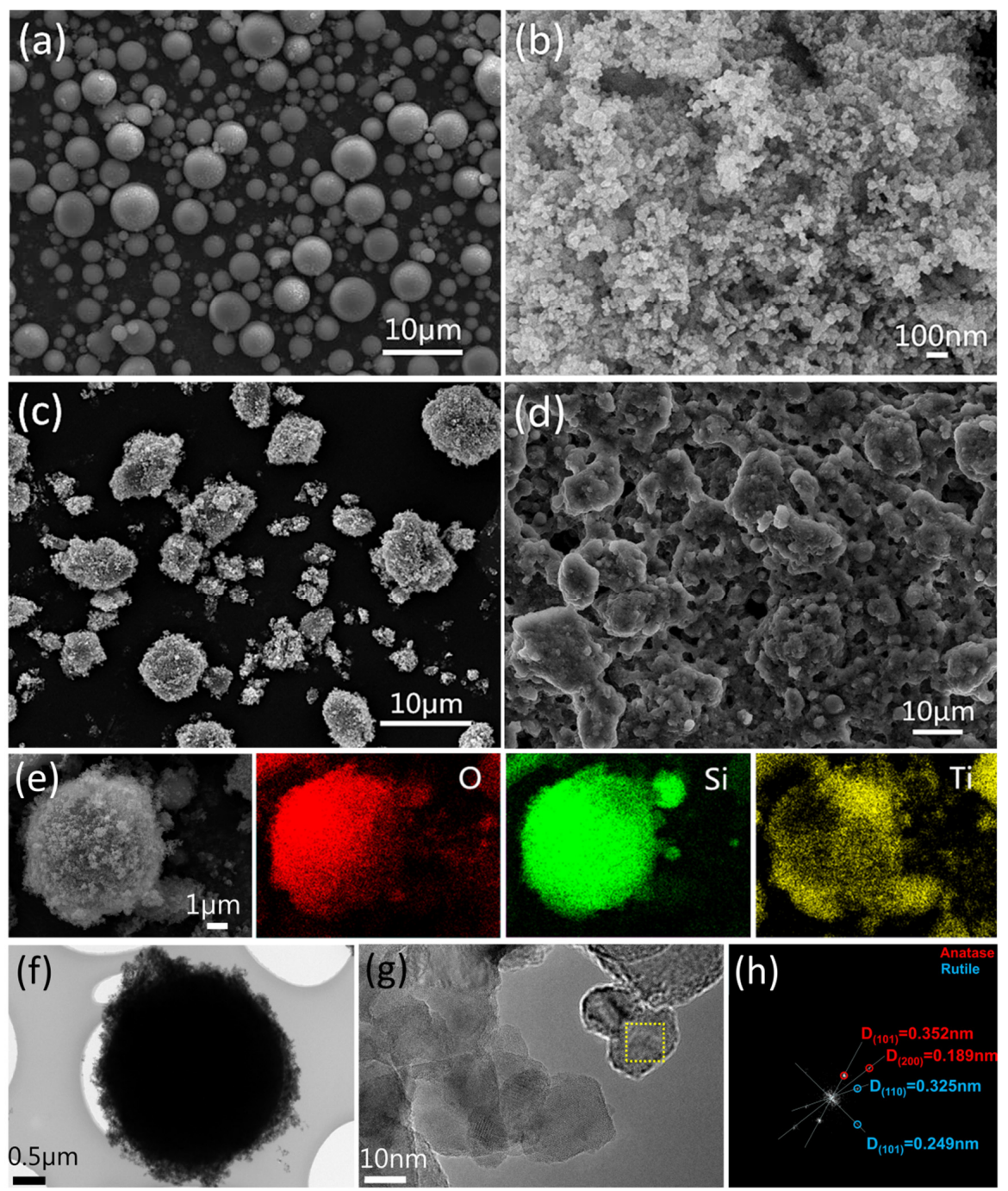

Figure 7. SEM images and EDS element mapping data of $\mathrm{A}-\mathrm{SiO}_{2}, \mathrm{~N}-\mathrm{TiO}_{2}$, and $\mathrm{A}-\mathrm{SiO}_{2} / \mathrm{N}-\mathrm{TiO}_{2}$. (a) SEM image of $\mathrm{A}-\mathrm{SiO}_{2}$; (b) SEM image of $\mathrm{N}-\mathrm{TiO}_{2}$; (c) SEM image of $\mathrm{A}-\mathrm{SiO}_{2} / \mathrm{N}-\mathrm{TiO}_{2}$; (d) SEM image of the $\mathrm{A}-\mathrm{SiO}_{2} / \mathrm{N}-\mathrm{TiO}_{2} @ \mathrm{PDMS}$ coating surface; (e) EDS element mapping images of $\mathrm{O}, \mathrm{Si}$, and Ti of $\mathrm{A}-\mathrm{SiO}_{2} / \mathrm{N}-\mathrm{TiO}_{2}$; (f) TEM of $\mathrm{A}-\mathrm{SiO}_{2} / \mathrm{N}-\mathrm{TiO}_{2}$; (g) HRTEM image of $\mathrm{A}-\mathrm{SiO}_{2} / \mathrm{N}-\mathrm{TiO}_{2}$; (h) FFT analysis of a selected area of $\mathrm{A}-\mathrm{SiO}_{2} / \mathrm{N}-\mathrm{TiO}_{2}$.

\subsubsection{Crystalline Phase}

The crystalline phases of samples can be characterized by X-ray diffractograms. Figure 8 displays the XRD patterns of samples. It was observed that $\mathrm{A}-\mathrm{SiO}_{2}$ had a peak of amorphous material around $2 \theta=21^{\circ}$, which indicated that the phase of $\mathrm{A}-\mathrm{SiO}_{2}$ was amorphous. There were several peaks in the diffractogram of $\mathrm{N}-\mathrm{TiO}_{2}$ corresponding to the crystal planes of anatase and rutile. The results manifested that $\mathrm{TiO}_{2}$ was composed of anatase and rutile. In the pattern of $\mathrm{A}-\mathrm{SiO}_{2} / \mathrm{N}-\mathrm{TiO}_{2}$, the peaks of anatase and rutile were clear, while the peak of amorphous material disappeared. This is because $\mathrm{A}-\mathrm{SiO}_{2}$ was covered by $\mathrm{N}-\mathrm{TiO}_{2}$. It was also demonstrated that $\mathrm{N}-\mathrm{TiO}_{2}$ was loaded on the $\mathrm{A}-\mathrm{SiO}_{2}$ surfaces successfully. The peak shape of the diffractogram of $\mathrm{A}-\mathrm{SiO}_{2} / \mathrm{N}-\mathrm{TiO}_{2} @ \mathrm{PDMS}$ was almost the same as that of $\mathrm{A}-\mathrm{SiO}_{2} / \mathrm{N}-\mathrm{TiO}_{2}$, and no new peak appeared. This is due to the fact that PDMS is an organic polymer, and it has no crystalline phase. 


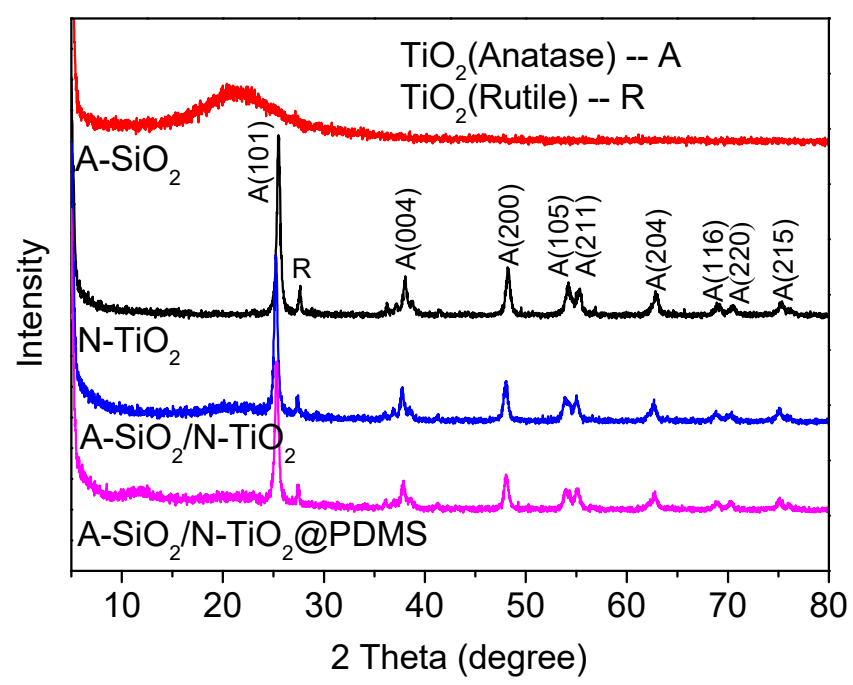

Figure 8. XRD patterns of $\mathrm{A}-\mathrm{SiO}_{2}, \mathrm{~N}-\mathrm{TiO}_{2}, \mathrm{~A}-\mathrm{SiO}_{2} / \mathrm{N}-\mathrm{TiO}_{2}$, and $\mathrm{A}-\mathrm{SiO}_{2} / \mathrm{N}-\mathrm{TiO}_{2} @ \mathrm{PDMS}$.

\subsubsection{FT-IR Spectrum}

According to the experimental phenomena discussed above, UV irradiation and calcination affected the surface properties of the superhydrophobic coating. Therefore, infrared spectra were used to test the changes in the surface functional groups of the samples. The infrared spectra of samples are presented in Figure 9. The peaks at $2960 \mathrm{~cm}^{-1}$, $2902 \mathrm{~cm}^{-1}, 1413 \mathrm{~cm}^{-1}$, and $1263 \mathrm{~cm}^{-1}$ were caused by the $-\mathrm{CH}_{3}$ of PDMS. Moreover, the peak at $802 \mathrm{~cm}^{-1}$ can be ascribed to the stretching vibration of Si-O-Si. The above peaks were caused by PDMS. The peaks at $1093 \mathrm{~cm}^{-1}$ and $1020 \mathrm{~cm}^{-1}$ were caused by the stretching vibration of Si-O. The broad peak at $3430 \mathrm{~cm}^{-1}$ can be ascribed to the $-\mathrm{OH}$ anti-symmetric stretching vibration peak of structured water, and the peak near $1634 \mathrm{~cm}^{-1}$ can be ascribed to the $\mathrm{H}-\mathrm{O}-\mathrm{H}$ bending vibration peak of water.

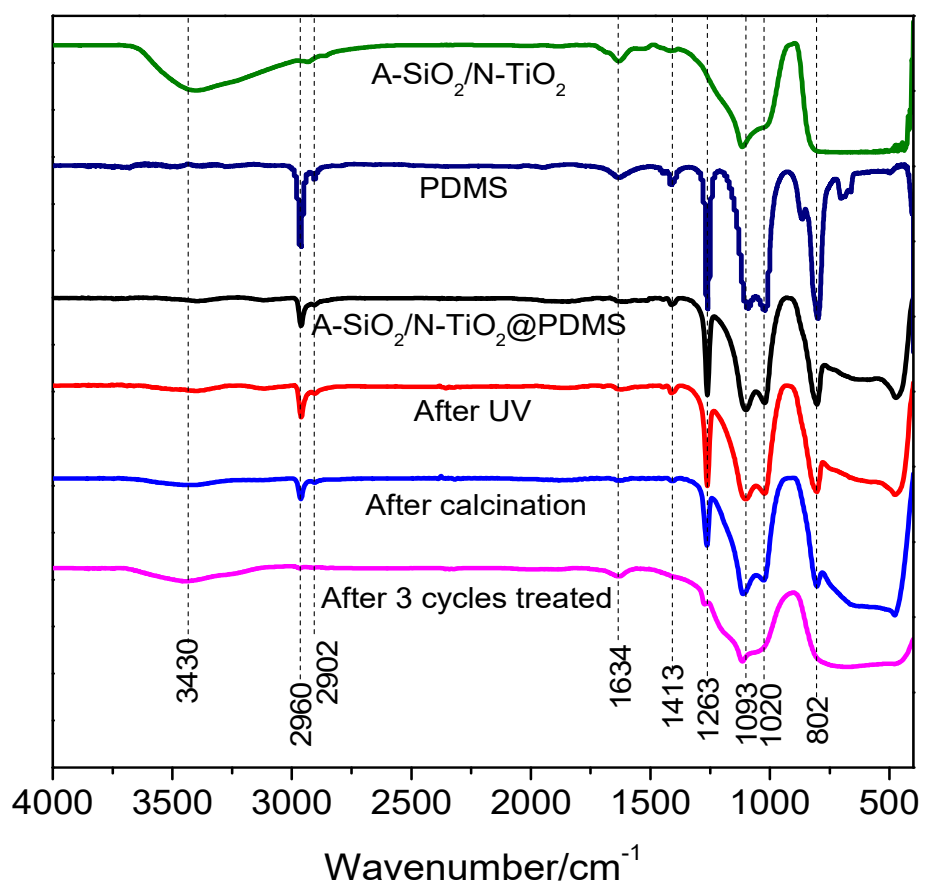

Figure 9. FT-IR spectra of $\mathrm{A}-\mathrm{SiO}_{2} / \mathrm{N}-\mathrm{TiO}_{2}, \mathrm{PDMS}, \mathrm{A}-\mathrm{SiO}_{2} / \mathrm{N}-\mathrm{TiO}_{2} @ \mathrm{PDMS}$, and $\mathrm{A}-\mathrm{SiO}_{2} / \mathrm{N}-$ $\mathrm{TiO}_{2} @ \mathrm{PDMS}$ after UV irradiation; $\mathrm{A}-\mathrm{SiO}_{2} / \mathrm{N}-\mathrm{TiO}_{2} @ \mathrm{PDMS}$ after calcination at $400{ }^{\circ} \mathrm{C}$; and $\mathrm{A}-\mathrm{SiO}_{2} / \mathrm{N}-$ $\mathrm{TiO}_{2} @ P D M S$ after 3 cycles of calcination and UV irradiation. 
It can be seen that the bending vibration peaks of $-\mathrm{OH}$ at $3430 \mathrm{~cm}^{-1}$ and $\mathrm{H}-\mathrm{O}-\mathrm{H}$ at $1634 \mathrm{~cm}^{-1}$ were clear in the spectrum of $\mathrm{A}-\mathrm{SiO}_{2} / \mathrm{N}-\mathrm{TiO}_{2}$. However, the above-mentioned peaks almost disappeared, and the peaks of PDMS could be seen in the spectrum of A$\mathrm{SiO}_{2} / \mathrm{N}-\mathrm{TiO}_{2} @ \mathrm{PDMS}$. This is because the $\mathrm{A}-\mathrm{SiO}_{2} / \mathrm{N}-\mathrm{TiO}_{2}$ was covered by PDMS. After UV irradiation, the peak shape did not significantly change, but the $-\mathrm{CH}_{3}$ peaks at $2960 \mathrm{~cm}^{-1}$ and $1263 \mathrm{~cm}^{-1}$ increased slightly, which indicates that the photocatalytic activity of N$\mathrm{TiO}_{2}$ could not decompose PDMS but might result in the rearrangement of hydrophobic groups, and more $-\mathrm{CH}_{3}$ appeared on the surface of the coating [23]. After calcination at $400{ }^{\circ} \mathrm{C}$, the characteristic peak of PDMS was weakened, indicating that part of PDMS might be decomposed during the process of calcination at $400{ }^{\circ} \mathrm{C}$. Moreover, the $-\mathrm{OH}$ peak at $3430 \mathrm{~cm}^{-1}$ was slightly enhanced, indicating that some -OH from $\mathrm{A}-\mathrm{SiO}_{2} / \mathrm{N}-\mathrm{TiO}_{2}$ was exposed on the surfaces. After three cycles of UV irradiation and calcination, the peaks of PDMS almost disappeared, and the shape of the spectrum was similar to that of $\mathrm{A}-\mathrm{SiO}_{2} / \mathrm{N}-\mathrm{TiO}_{2}$. This indicates that PDMS was completely decomposed during the cycles of UV irradiation and calcination. Moreover, the bending vibration peaks of $-\mathrm{OH}$ at $3430 \mathrm{~cm}^{-1}$ and $\mathrm{H}-\mathrm{O}-\mathrm{H}$ at $1634 \mathrm{~cm}^{-1}$ increased, indicating that more -OH was exposed on the surface.

\subsubsection{XPS Spectra}

To further investigate the reactions between PDMS and composite particles, XPS was carried out. Figure 10 a shows the full-spectrum XPS scan of A-SiO $2 / \mathrm{N}-\mathrm{TiO}_{2}, \mathrm{~A}-\mathrm{SiO}_{2} / \mathrm{N}-$ $\mathrm{TiO}_{2} @ \mathrm{PDMS}, \mathrm{A}-\mathrm{SiO}_{2} / \mathrm{N}-\mathrm{TiO}_{2} @ \mathrm{PDMS}$ after UV irradiation, $\mathrm{A}-\mathrm{SiO}_{2} / \mathrm{N}-\mathrm{TiO}_{2} @ \mathrm{PDMS}$ after calcination at $400{ }^{\circ} \mathrm{C}$, and $\mathrm{A}-\mathrm{SiO}_{2} / \mathrm{N}-\mathrm{TiO}_{2} @ \mathrm{PDMS}$ after three cycles of UV irradiation and calcination. Figure 10b-f show the narrow-scan spectra of $\mathrm{O} 1 \mathrm{~s}$ in the above-mentioned spectra. Comparing the peak of $C 1$ s, the intensity of $C$ 1s peak was the highest in the $\mathrm{A}-\mathrm{SiO}_{2} / \mathrm{N}-\mathrm{TiO}_{2} @ \mathrm{PDMS}$ spectrum, which was caused by the large amount of $\mathrm{C}$ bond in PDMS. After UV irradiation, the $C 1$ s peak did not change significantly, but it decreased dramatically after calcination and three cycles of UV irradiation and calcination, indicating that $\mathrm{C}-\mathrm{H}$ or $\mathrm{C}-\mathrm{Si}$ bonds were fractured during the process. The change in the $\mathrm{C} 1 \mathrm{~s}$ peak was consistent with the result of the FT-IR. Comparing the Ti $2 p$ peaks, their intensity increased slightly after UV irradiation, which might be due to the generation of new Ticontaining bonds after UV irradiation. Moreover, it further increased in the spectra of $\mathrm{A}-\mathrm{SiO}_{2} / \mathrm{N}-\mathrm{TiO}_{2} @ \mathrm{PDMS}$ after calcination and $\mathrm{A}-\mathrm{SiO}_{2} / \mathrm{N}-\mathrm{TiO}_{2} @ \mathrm{PDMS}$ after three cycles of UV irradiation and calcination. This illustrates that new Ti-containing bonds might be generated after calcination. Meanwhile, more $\mathrm{N}-\mathrm{TiO}_{2}$ was exposed, and the intensity of the Ti $2 p$ peak was further enhanced due to the thermal decomposition of some $C$ bonds. By comparing the peaks of $\mathrm{O} 1 \mathrm{~s}$, it was noted that the intensity of peaks did not significantly change before or after UV irradiation. However, the intensity of the $\mathrm{O} 1$ s peak notably increased in the spectra of $\mathrm{A}-\mathrm{SiO}_{2} / \mathrm{N}-\mathrm{TiO}_{2} @ \mathrm{PDMS}$ after calcination and three cycles of UV irradiation and calcination. The reason for this phenomenon is similar to that of the strengthening of the Ti $2 p$ peak mentioned above, i.e., the generation of new O-containing bonds and the thermal decomposition of some $\mathrm{C}$-containing bonds might result in the exposure of more $\mathrm{N}-\mathrm{TiO}_{2}$ and $\mathrm{A}-\mathrm{SiO}_{2}$ on the surface. 
(a)

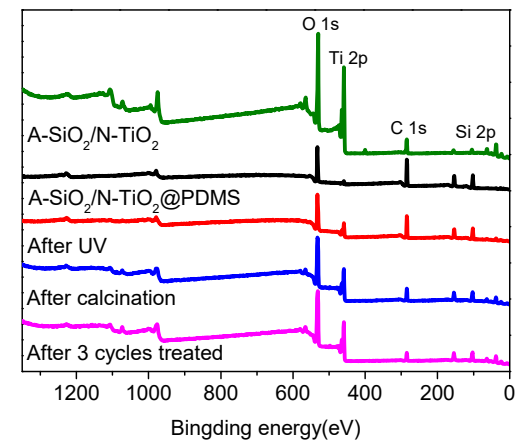

(c)

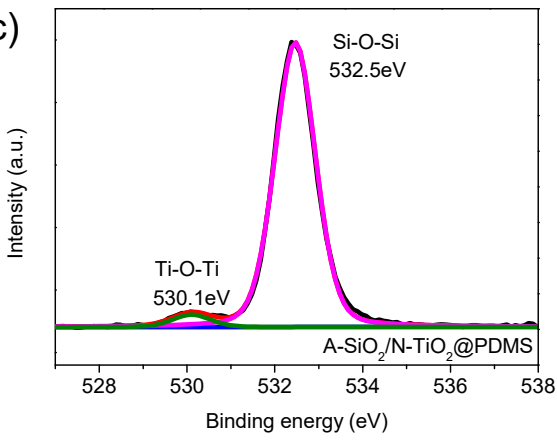

(e)

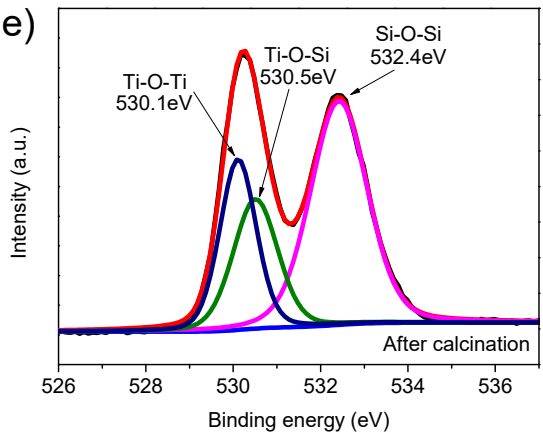

(b)

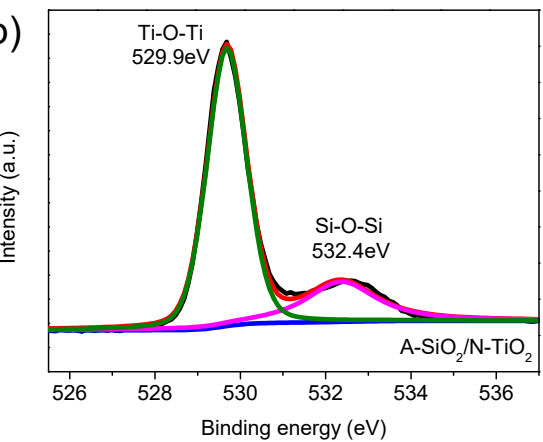

(d)

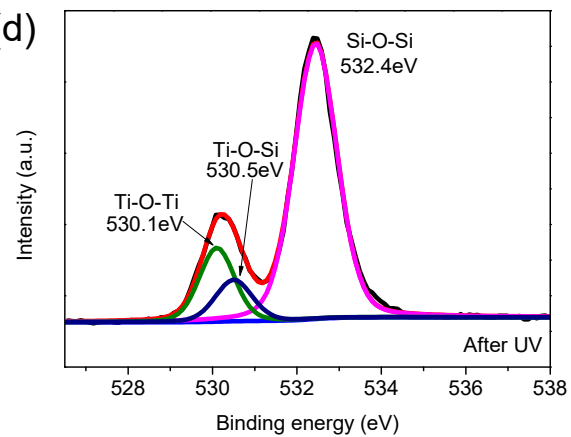

(f)

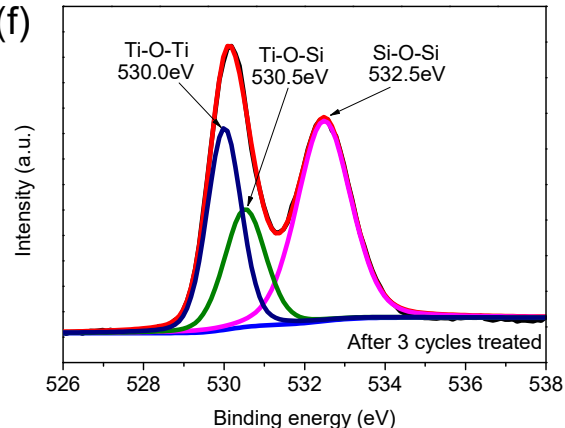

Figure 10. (a) Full-scan XPS spectra of $\mathrm{A}-\mathrm{SiO}_{2} / \mathrm{N}-\mathrm{TiO}_{2}, \mathrm{~A}-\mathrm{SiO}_{2} / \mathrm{N}-\mathrm{TiO}_{2} @ \mathrm{PDMS}, \mathrm{A}-\mathrm{SiO}_{2} / \mathrm{N}-\mathrm{TiO}_{2} @ \mathrm{PDMS}$ after UV irradiation; $\mathrm{A}-\mathrm{SiO}_{2} / \mathrm{N}-\mathrm{TiO}_{2} @ \mathrm{PDMS}$ after calcination at $400{ }^{\circ} \mathrm{C}$; and $\mathrm{A}-\mathrm{SiO}_{2} / \mathrm{N}-\mathrm{TiO}_{2} @ \mathrm{PDMS}$ after three cycles of UV irradiation and calcination. (b-f) Narrow-scan spectra of $\mathrm{O} 1 \mathrm{~s}$ in the above spectra.

Figure $10 \mathrm{~b}$ shows that, in the spectrum of $\mathrm{A}-\mathrm{SiO}_{2} / \mathrm{N}-\mathrm{TiO}_{2}, \mathrm{O}$ 1s could be divided into two parts, which were caused by Ti-O-Ti and Si-O-Si. Furthermore, the peak at $529.9 \mathrm{eV}$ was much higher than that of $532.4 \mathrm{eV}$. This is because $\mathrm{A}-\mathrm{SiO}_{2}$ was covered by $\mathrm{N}-\mathrm{TiO}_{2}$. Figure 10c shows the spectrum of $\mathrm{A}-\mathrm{SiO}_{2} / \mathrm{N}-\mathrm{TiO}_{2} @ \mathrm{PDMS}$. The Si-O-Si peak was much higher than that of Ti-O-Ti, which is because a considerable amount of Si-O-Si existed in the PDMS. Figure 10d shows the $\mathrm{O}$ 1s peak of $\mathrm{A}-\mathrm{SiO}_{2} / \mathrm{N}-\mathrm{TiO}_{2} @ \mathrm{PDMS}$ after UV irradiation. The intensity of the $\mathrm{O} 1 \mathrm{~s}$ peak at around $530 \mathrm{eV}$ increased after UV irradiation and this peak could be divided into two peaks at $530.1 \mathrm{eV}$ and $530.5 \mathrm{eV}$, which were attributed to Ti-O-Ti and Ti-O-Si, respectively. It was demonstrated that the Ti-O-Si bond was formed by the reaction of $\mathrm{N}-\mathrm{TiO}_{2}$ and $\mathrm{PDMS}$ under UV irradiation [20]. The spectrum of $\mathrm{A}-\mathrm{SiO}_{2} / \mathrm{N}-$ $\mathrm{TiO}_{2} @ \mathrm{PDMS}$ after $400{ }^{\circ} \mathrm{C}$ calcination is shown in Figure 10e. The intensity of the $\mathrm{O}$ 1s peak (binding energy $532.4 \mathrm{eV}$ ) corresponding to the $\mathrm{Si}-\mathrm{O}-\mathrm{Si}$ bond was lower than that before calcination. It was attributed to the thermal decomposition of PDMS and the hydrolysis of PDMS to form silanol groups. The intensity of the O 1s peak corresponding to Ti-O$\mathrm{Ti}$ and Ti-O-Si bonds was higher than that before calcination. This meant that PDMS could react with $\mathrm{N}-\mathrm{TiO}_{2}$ on the surface of the coating to form Ti-O-Si bonds during the 
calcination process. Additionally, more $\mathrm{N}-\mathrm{TiO}_{2}$ was exposed on the surface because of the thermal decomposition of some PDMS. As a result, the intensity of the Ti-O-Ti bond also significantly increased. In Figure 10f, the intensity of the $\mathrm{O}$ 1s peak corresponding to the $\mathrm{Si}-\mathrm{O}-\mathrm{Si}$ bond further decreased in the spectrum of $\mathrm{A}-\mathrm{SiO}_{2} / \mathrm{N}-\mathrm{TiO}_{2} @ \mathrm{PDMS}$ after three cycles of UV irradiation and calcination. Moreover, the intensity of the $\mathrm{O} 1$ s peak corresponding to Ti-O-Ti and Ti-O-Si bonds, especially the intensity of the $\mathrm{O} 1$ s peak corresponding to Ti-O-Ti, further increased. This is because the thermal decomposition of PDMS tended to be complete, and the hydrophobic groups were exhausted. More $\mathrm{N}-\mathrm{TiO}_{2}$ was exposed on the surface, which further strengthened the Ti-O-Ti bond.

\subsection{Mechanism}

In this study, the mechanism of the self-cleaning property of an as-prepared coating was analyzed according to the experimental phenomena, test results, and existing research results. Figure 11 shows the microstructure, wetting state, and reaction mechanism of the coating after UV irradiation and calcination at $400^{\circ} \mathrm{C}$.

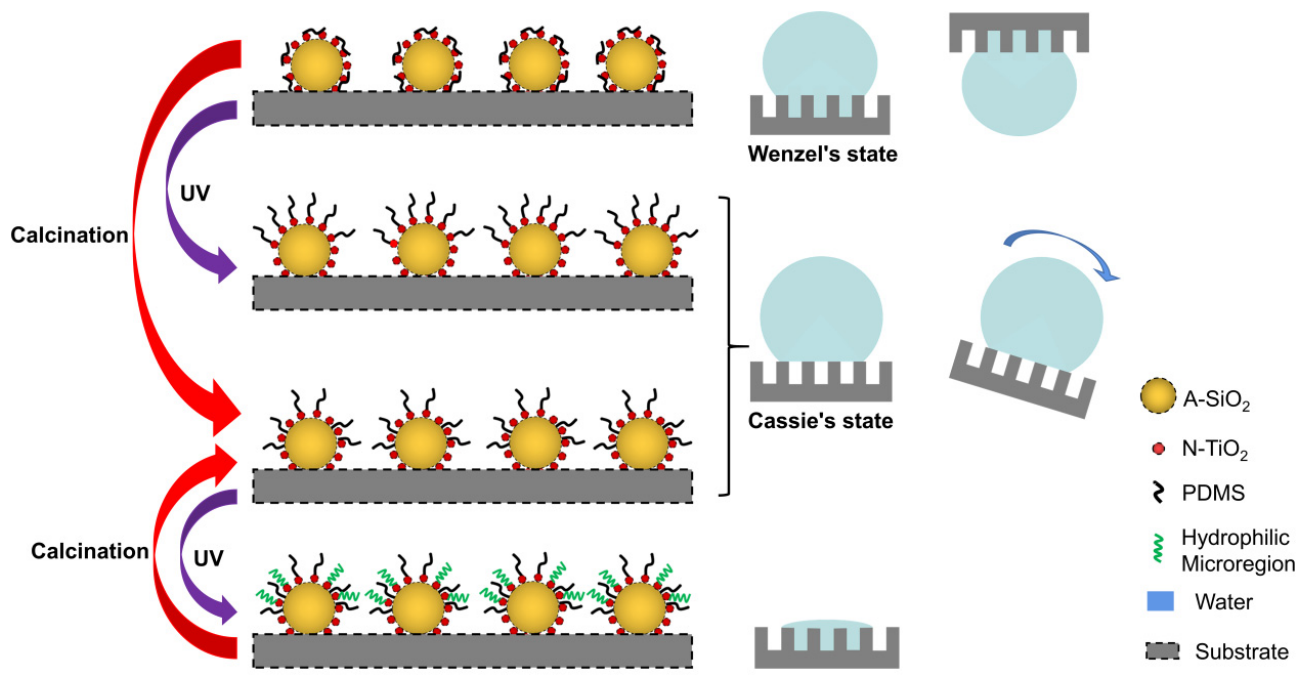

Figure 11. Wetting state and surface microstructure of the $\mathrm{A}-\mathrm{SiO}_{2} / \mathrm{N}-\mathrm{TiO}_{2} @ \mathrm{PDMS}$ coating under different conditions.

Firstly, the mechanism of the superhydrophobicity and high adhesion of the coating is as follows: The superhydrophobicity of the coating was caused by the hierarchical structure of A-SiO $2 / \mathrm{N}-\mathrm{TiO}_{2}$ and the low surface energy of PDMS [24,25]. The adhesion of its surface was due to the fact that $\mathrm{A}-\mathrm{SiO}_{2} / \mathrm{N}-\mathrm{TiO}_{2}$ might not be covered by PDMS completely, and a small part of -OH was exposed on the surfaces. The hydrophilicity of -OH resulted in high adhesion to water droplets [26]. At this time, the surface of the coating was in Wenzel's state.

Secondly, the mechanism of the increase in superhydrophobicity and decrease in adhesion of the coating after UV irradiation is as follows: $\mathrm{N}-\mathrm{TiO}_{2}$ produced electron-hole pairs under UV irradiation. Then, the electron-hole pairs may have excited the generation of hydroxyl groups and water molecules. The activated molecules partially cleaved siloxane bonds of PDMS. These segmented siloxane-based chains formed a covalent bond with $\mathrm{N}-\mathrm{TiO}_{2}$ via a Ti-O-Si bond, resulting in the occupation of hydroxyl groups and the existence of more hydrophobic groups on the coating surface [23]. At this time, the surface of the coating was in Cassie's state. The reaction mechanism is illustrated in Figure S2.

Thirdly, the mechanism of the increase in superhydrophobicity and decrease in adhesion of the coating after calcination at $400{ }^{\circ} \mathrm{C}$ is discussed below. At this time, the surface of the coating was still in Cassie's state. The mechanism is analyzed as follows: water molecules on the surface reacted with PDMS, and PDMS hydrolyzed to form silanol groups 
which condensed with the hydroxyl groups of $\mathrm{A}-\mathrm{SiO}_{2}$ and $\mathrm{N}-\mathrm{TiO}_{2}$, thus forming $\mathrm{Si}-\mathrm{O}-\mathrm{Si}$ and Si-O-Ti bonds [27]. This caused PDMS to be grafted onto the $\mathrm{A}-\mathrm{SiO}_{2}$ and $\mathrm{N}-\mathrm{TiO}_{2}$ surfaces. The mechanism is shown in Figure S3. A part of the decomposed PDMS formed Si-O-Si bonds with $\mathrm{SiO}_{2}$, so the Ti hydroxyl groups on the coating surface were not completely occupied. This led to the exposure of some $\mathrm{N}-\mathrm{TiO}_{2}$ on the surface. This is the reason why the calcined $\mathrm{A}-\mathrm{SiO}_{2} / \mathrm{N}-\mathrm{TiO}_{2} @ \mathrm{PDMS}$ coating surface lost its superhydrophobicity after UV irradiation.

Fourth is the mechanism of the reversible wettability of the coating after UV irradiation and calcination. As mentioned above, PDMS could form covalent bonds with $\mathrm{A}-\mathrm{SiO}_{2}$ and $\mathrm{N}-\mathrm{TiO}_{2}$ via $\mathrm{Si}-\mathrm{O}-\mathrm{Si}$ and $\mathrm{Si}-\mathrm{O}-\mathrm{Ti}$ bonds under calcination at $400{ }^{\circ} \mathrm{C}$. However, some Ti hydroxyls might not have reacted with PDMS, and they were exposed on the surface. Electron-hole pairs were generated on the surface of $\mathrm{N}^{-\mathrm{TiO}_{2}}$ under $\mathrm{UV}$ irradiation. The electron reacted with $\mathrm{Ti}^{4+}$, and the hole reacted with the surface bridging oxygen, forming $\mathrm{Ti}^{3+}$ and oxygen vacancy, respectively. At this time, water in the air was absorbed by the oxygen vacancies and became chemisorbed water. The chemisorbed water further adsorbed moisture in the air to form hydrophilic micro-regions around $\mathrm{Ti}^{3+}$ defects. The water on the surface was absorbed by the hydrophilic micro-regions, so the surface of the coating was hydrophilic [28]. After calcination at $400{ }^{\circ} \mathrm{C}$ for $2 \mathrm{~h}$, the wettability of the as-prepared coating changed from hydrophilicity to superhydrophilicity. This is because the chemisorbed hydroxyl was replaced by oxygen in the air after calcination, and the hydrophilic micro-regions disappeared. The wettability of the as-prepared coating could not change from hydrophilicity to superhydrophilicity after three cycles of UV irradiation and calcination, because PDMS was exhausted during the process of repeated UV irradiation and calcination, and the hydrophobic groups almost completely disappeared. Eventually, the $\mathrm{A}-\mathrm{SiO}_{2} / \mathrm{N}-\mathrm{TiO}_{2} @ \mathrm{PDMS}$ coating showed a hydrophilic state.

\section{Conclusions}

In conclusion, cheap and nontoxic $\mathrm{A}-\mathrm{SiO}_{2}$ composites were selected as carriers, and the $\mathrm{A}-\mathrm{SiO}_{2} / \mathrm{N}-\mathrm{TiO}_{2}$ composites were prepared by the hydrophobic aggregation method. Then, the $\mathrm{A}-\mathrm{SiO}_{2} / \mathrm{N}-\mathrm{TiO}_{2}$ composites were modified with PDMS. Finally, the intelligent superhydrophobic A-SiO $2 / \mathrm{N}-\mathrm{TiO}_{2} @ \mathrm{PDMS}$ coating was formed by the spraying method. The WCA of the coating was further enhanced, and its CAH was decreased after UV irradiation and calcination at $400{ }^{\circ} \mathrm{C}$. The $\mathrm{A}-\mathrm{SiO}_{2} / \mathrm{N}-\mathrm{TiO}_{2} @ \mathrm{PDMS}$ was suitable for constructing self-cleaning coatings on the surfaces of different types of substrates, such as glass, wood, foam, concrete, and brick. Moreover, the coating maintained self-cleaning properties after being placed outdoors for 3 months, showing a good adaptability to the outdoor environment. Therefore, the $\mathrm{A}-\mathrm{SiO}_{2} / \mathrm{N}-\mathrm{TiO}_{2} @ \mathrm{PDMS}$ could be used to construct a self-cleaning coating with superhydrophobicity, low adhesion to water droplets, and photocatalytic activity under ultraviolet or sunlight irradiation. The coating not only had the excellent self-cleaning properties but also the advantages of cheap and readily available raw materials, a simple preparation process, being pollution-free, and broad practical application prospects.

Supplementary Materials: The following are available online at https:/ /www.mdpi.com/article/10 .3390/nano11061486/s1, Table S1: The wettability and adhesion force of the A-SiO2/N-TiO2@PDMS coating to water droplets before and after UV/sun irradiation and calcination, Table S2: CAs of the surfaces of a glass slide and the A-SiO2/N-TiO2@PDMS coating after UV irradiation to different droplets, Figure S1: TG curves of A-SiO2/TiO2 and A-SiO2/TiO2@PDMS, Figure S2: Reaction mechanism of PDMS and N-TiO2 under UV irradiation, Figure S3: Reaction mechanism of PDMS with $\mathrm{N}-\mathrm{TiO} 2$ and $\mathrm{A}-\mathrm{SiO} 2$ under calcination at $400{ }^{\circ} \mathrm{C}$.

Author Contributions: Conceptualization, X.W. and W.A.; methodology, X.W.; software, S.S.; validation, H.Z., R.Z. and Y.L.; formal analysis, J.W.; investigation, X.W.; resources, W.A.; data curation, H.D.; writing - original draft preparation, X.W.; writing - review and editing, X.W.; visualization, W.A.; supervision, W.A.; project administration, H.D.; funding acquisition, W.A., and H.D. All authors have read and agreed to the published version of the manuscript. 
Funding: This research was funded by the National Natural Science Foundation of China, grant number 51474194) and the Fundamental Research Funds for the Central Universities of China, grant number 292019162.

Conflicts of Interest: The authors have declared that there are no competing interests existing in this research.

\section{References}

1. Barthlott, W.; Neinhuis, C. Purity of the sacred lotus, or escape from contamination in biological surfaces. Planta 1997, 202, 1-8. [CrossRef]

2. Feng, L.; Zhang, Y.; Xi, J.; Zhu, Y.; Wang, N.; Xia, F.; Jiang, L. Petal effect: A superhydrophobic state with high adhesive force. Langmuir 2008, 24, 4114-4119. [CrossRef]

3. Wang, P.; Yang, Y.; Wang, H.; Wang, H. Fabrication of super-robust and nonfluorinated superhydrophobic coating based on diatomaceous earth. Surf. Coat. Tech. 2019, 362, 90-96. [CrossRef]

4. Lu, Y.; Sathasivam, S.; Song, J.; Crick, C.R.; Carmalt, C.J.; Parkin, P. Robust self-cleaning surfaces that function when exposed to either air or oil. Science 2015, 347, 1132-1135. [CrossRef] [PubMed]

5. Qing, W.; Shi, X.; Deng, Y.; Zhang, W.; Wang, J.; Tang, C.Y. Robust superhydrophobic-superoleophilic polytetrafluoroethylene nanofibrous membrane for oil/water separation. J. Membr. Sci. 2017, 540, 354-361. [CrossRef]

6. Sun, S.; Zhu, L.; Liu, X.; Wu, L.; Dai, K.; Liu, C.; Shen, C.; Guo, X.; Zheng, G.; Guo, Z. Superhydrophobic Shish-kebab Membrane with Self-Cleaning and Oil/Water Separation Properties. ACS Sustain. Chem. Eng. 2018, 6, 9866-9875. [CrossRef]

7. Qing, Y.; Yang, C.; Yu, N.; Shang, Y.; Sun, Y.; Wang, L.; Liu, C. Superhydrophobic $\mathrm{TiO}_{2} /$ polyvinylidene fluoride composite surface with reversible wettability switching and corrosion resistance. Chem. Eng. J. 2016, 290, 37-44. [CrossRef]

8. Wen, G.; Guo, Z.; Liu, W. Biomimetic polymeric superhydrophobic surfaces and nanostructures: From fabrication to applications. Nanoscale 2017, 9, 3338-3366. [CrossRef]

9. Wang, Y.; Lai, H.; Cheng, Z.; Zhang, H.; Liu, Y.; Jiang, L. Smart Superhydrophobic Shape Memory Adhesive Surface toward Selective Capture/Release of Microdroplets. ACS Appl. Mater. Inter. 2019, 11, 10988-10997. [CrossRef]

10. Wang, Z.; Cao, J.; Jia, J.; Qi, J.; Huang, Y.; Feng, J. Making Superhydrophobic Surfaces with Microstripe Array Structure by Diffusion Bonding and Their Applications in Magnetic Control Microdroplet Release Systems. Adv. Mater. Interfaces 2017, 4 , 1700918. [CrossRef]

11. Liu, K.; Cao, M.; Fujishima, A.; Jiang, L. Bio-inspired titanium dioxide materials with special wettability and their applications. Chem. Rev. 2014, 114, 10044-10094. [CrossRef]

12. Liu, L.; Chen, X. Titanium dioxide nanomaterials: Self-structural modifications. Chem. Rev. 2014, 114, 9890-9918. [CrossRef]

13. Schneider, J.; Matsuoka, M.; Takeuchi, M.; Zhang, J.; Horiuchi, Y.; Anpo, M.; Bahnemann, D.W. Understanding TiO 2 photocatalysis: Mechanisms and materials. Chem. Rev. 2014, 114, 9919-9986. [CrossRef] [PubMed]

14. Nakata, K.; Fujishima, A. $\mathrm{TiO}_{2}$ photocatalysis: Design and applications. J. Photoch. Photobio. C 2012, 13, 169-189. [CrossRef]

15. Shayegan, Z.; Lee, C.; Haghighat, $\mathrm{F}$. $\mathrm{TiO}_{2}$ photocatalyst for removal of volatile organic compounds in gas phase - A review. Chem. Eng. J. 2017, 334, 2408-2439. [CrossRef]

16. Crick, C.R.; Bear, J.C.; Kafizas, A.; Parkin, I.P. Superhydrophobic photocatalytic surfaces through direct incorporation of titania nanoparticles into a polymer matrix by aerosol assisted chemical vapor deposition. Adv. Mater. 2012, 24, 3505-3508. [CrossRef] [PubMed]

17. Zhang, X.; Liu, S.; Salim, A.; Seeger, S. Hierarchical Structured Multifunctional Self-Cleaning Material with Durable Superhydrophobicity and Photocatalytic Functionalities. Small 2019, 15, 1901822. [CrossRef]

18. Xu, Q.; Liu, Y.; Lin, F.; Mondal, B.; Lyons, A.M. Superhydrophobic $\mathrm{TiO}_{2}$-Polymer Nanocomposite Surface with UV-Induced Reversible Wettability and Self-Cleaning Properties. ACS Appl. Mater. Inter. 2013, 5, 8915-8924. [CrossRef]

19. Chen, K.; Zhou, S.; Wu, L. Facile fabrication of self-repairing superhydrophobic coatings. Chem. Commun. 2014, 50, 11891-11894. [CrossRef]

20. Peng, S.; Meng, W.; Guo, J.; Wang, B.; Wang, Z.; Xu, N.; Li, X.; Wang, J.; Xu, J. Photocatalytically Stable Superhydrophobic and Translucent Coatings Generated from PDMS-Grafted-SiO $2 / \mathrm{TiO}_{2} @ P D M S$ with Multiple Applications. Langmuir 2019, 35, 2760-2771. [CrossRef] [PubMed]

21. Yao, W.; Bae, K.; Jung, M.Y.; Cho, Y. Transparent, conductive, and superhydrophobic nanocomposite coatings on polymer substrate. J. Colloid. Interface Sci. 2017, 506, 429-436. [CrossRef]

22. Sun, S.; Ding, H.; Hou, X.; Chen, D.; Yu, S.; Zhou, H.; Chen, Y. Effects of organic modifiers on the properties of TiO ${ }_{2}-\mathrm{coated}$ $\mathrm{CaCO}_{3}$ composite pigments prepared by the hydrophobic aggregation of particles. Appl. Surf. Sci. 2018, 456, 923-931. [CrossRef]

23. Wooh, S.; Encinas, N.; Vollmer, D.; Butt, H. Stable Hydrophobic Metal-Oxide Photocatalysts via Grafting Polydimethylsiloxane Brush. Adv. Mater. 2017, 29, 1604637. [CrossRef] [PubMed]

24. Wang, S.; Liu, K.; Jiang, L.; Yao, X. Bioinspired Surfaces with Superwettability: New Insight on Theory, Design, and Applications. Chem. Rev. 2015, 115, 8023-8093. [CrossRef] [PubMed]

25. Tian, Y.; Su, B.; Jiang, L. Interfacial Material System Exhibiting Superwettability. Adv. Mater. 2014, 26, 6872-6897. [CrossRef] [PubMed]

26. Wang, S.; Jiang, L. Definition of Superhydrophobic States. Adv. Mater. 2010, 19, 3423-3424. [CrossRef] 
27. Krumpfer, J.; Mccarthy, T. Rediscovering Silicones: “Unreactive Silicones” React with Inorganic Surfaces. Langmuir 2011, 27, 11514-11519. [CrossRef]

28. Fujishima, A.; Rao, T.; Tryk, D. Titanium dioxide photocatalysis. J. Photoch. Photobio. C 2000, 1, 1-21. [CrossRef] 